\title{
KARAKTERISTIK DAN MOTIVASI WISATAWAN MANCANEGARA BERKUNJUNG KE PANTAI JEMELUK-AMED, DESA PURWAKERTI, KECAMATAN ABANG, KARANGASEM
}

\author{
Helmi Cahyana ${ }^{1}$, I Ketut Suwena ${ }^{2}$, I Putu Sudana ${ }^{3}$ \\ 1Email: helmicahyana93@gmail.com \\ Program Studi S1 Industri Perjalanan Wisata, Fakultas Pariwisata, Universitas Udayana \\ ${ }^{2}$ Email: suwenaketut31@gmail.com \\ Program Studi S1 Industri Perjalanan Wisata, Fakultas Pariwisata, Universitas Udayana \\ ${ }^{3}$ Email: sudanaputu@yahoo.com \\ Program Studi S1 Industri Perjalanan Wisata, Fakultas Pariwisata, Universitas Udayana
}

\begin{abstract}
Jemeluk-Amed Beach is a marine tourism destination in the Purwakerti Village. Marine tourism which has a potential in variety of coral reef maintained continuity. Jemeluk-Amed beach has a wide range of tourism activities such as snorkeling, diving, canoeing, and sailing. Travelers who come to visit Jemeluk-Amed Beach certainly has the characteristics and motivations are different from each other. The purpose of this study was to determine the characteristics and motivations of foreign tourists who visited Jemeluk-Amed Beach, Karangasem. The method used to determine the rating by trip characteristics and tourist descriptor, while the tourist motivation is classified into four groups: the physical motivation, cultural motivation, social motivation, motivation fantasy. A total 110 questionnaire were distributed by field research to tourist as a respondent. The results of the questionnaire then processed quantitative presented in the form of tables and analysis of qualitative data in the form of a narrative text according to the research objectives. The research results showed that foreign tourists visited Jemeluk-Amed Beach is dominated by tourists from The Europe Continent with an average age of 26-35 years (53.64\%); the average length of stay 1-3 days (78.18\%); most of travelers visited is drifter tourists. Tourist motivation mostly physical stated motivation as a reason to visited; partly motivated to exercise (sports) as much as $40.91 \%$ of the overall respondents. Travelers visited for fun (28.18\%) of the overall respondents. Suggestions of this study are expected to be contribute ideas to The Government of Karangasem and for groups of fishermen Tunas Mekar and Mina Prami.
\end{abstract}

\begin{abstract}
Abstrak: Pantai Jemeluk-Amed merupakan destinasi wisata bahari yang berada di Desa Purwakerti, yang memiliki potensi terumbu karang yang beraneka ragam jenis. Di Pantai Jemeluk-Amed tersedia berbagai macam aktivitas wisata diantaranya snorkeling, diving, canoeing, dan sailing. Wisatawan yang datang mengunjungi Pantai Jemeluk-Amed tentunya memiliki karakteristik dan motivasi yang berbeda satu sama lain. Tujuan dari penelitian ini adalah untuk mengetahui karakteristik dan motivasi wisatawan mancanegara yang berkunjung ke Pantai Jemeluk-Amed, Karangasem. Metode yang digunakan untuk mengetahui karakteristik wisatawan berdasarkan trip descriptor dan tourist descriptor, sedangkan motivasi wisatawan dikelompokan kedalam empat kelompok yaitu physical motivation, cultural motivation, social motivation, fantasy motivation. Pengumpulan data dilakukan dengan kuesioner kepada 110 responden. Hasil kuesioner kemudian diolah secara kuantitatifyang disajikan kedalam bentuk tabel dan dilakukan analisis data secara kualitatif dalam bentuk teks naratif sesuai dengan tujuan penelitian. Hasil penelitian menunjukan bahwa wisatawan mancanegara yang berkunjung ke Pantai Jemeluk-Amed paling banyak wisatawan dari Benua Eropa dengan rata-rata usia 26-35 tahun (53.64\%); rata-rata lama kunjungan 1-3 hari (78.18\%); wisatawan yang berkunjung kebanyakan wisatawan drifter. Motivasi wisatawan sebagian besar menyatakan physical motivation sebagai alasan berkunjung; sebagian motivasi berolahraga (sport) sebanyak $40.91 \%$ dari keseluruhan responden. Wisatawan berkunjung untuk bersenang-senang sebesar $28.18 \%$ dari keseluruhan responden.
\end{abstract}

Keywords: characteristics, motivation, foreign tourists. 


\section{PENDAHULUAN}

Pariwisata Indonesia menjadi industri yang sangat diandalkan dalam penerimaan keuangan negara serta dalam pembangunan nasional karena pariwisata dapat meningkatkan pendapatan nasional, daerah, serta devisa negara. Di tahun 2019 Kementrian Pariwisata, industri pariwisata memproyeksikan menjadi penghasil devisa terbesar di Indonesia yaitu USD 24 milliar, melampaui penerimaan sektor migas, batubara dan minyak kelapa sawit. Selain itu, penerimaan devisa sektor pariwisata yang masuk langsung bisa dirasakan oleh seluruh lapisan masyarakat. Karena adanya multiplier effect yang tinggi dan amat luas.

Indonesia kaya akan potensi alam yang luar biasa, seperti garis pantai yang panjang, gunung yang banyak, budaya dan kekayaan kuliner menjadi aset pengembangan pariwisata nasional. Indonesia memiliki beragam destinasi wisata yang sudah dikenal oleh dunia merupakan salah satu keuntungan. Wilayah Indonesia yang terdiri atas laut, daratan, dan pegunungan merupakan modal yang sangat besar untuk dikembangkan dengan berbagai jenis daya tarik wisata. Berkaitan dengan pariwisata, nama pulau Bali tidak mungkin ditinggalkan. pulau Bali merupakan salah satu pulau yang dikenal penjuru belahan dunia dengan keindahan alam dan budaya. Alam dan budaya Bali sampai sekarang masih mampu mempesona para wisatawan mancanegara. Alam pulau Bali yang terdiri atas laut, gunung, danau, hutan, dan panorama alam yang masih asri merupakan modal besar untuk pengembangan kepariwisataan Indonesia. Pulau Bali memang sangat menarik sehingga tidak dapat dipungkiri bahwa Bali sebagai tujuan berlibur. Selain itu, keramahtamahan penduduk menjadikan Bali memiliki jumlah kunjungan wisatawan mancanegara yang tinggi di Indonesia.

Perkembangan arus wisatawan asing berkunjung ke pulau Bali dari tahun ketahun menunjukan peningkatan. Indikator ini mencerminkan harapan bahwa Bali masih baik di masa mendatang. Berikut data jumlah kunjungan wisatawan mancanegara ke Pulau Bali dalam kurun waktu lima tahun terakhir dapat dilihat pada Tabel 1.
Tabel 1. Jumlah Kunjungan Wisatawan Mancanegara ke Pulau Bali Pada Periode Tahun 2012 - 2016

\begin{tabular}{ccc}
\hline Tahun & $\begin{array}{c}\text { Jumlah } \\
\text { Kunjungan } \\
\text { (orang) }\end{array}$ & $\begin{array}{c}\text { Pertumbuhan } \\
(\%)\end{array}$ \\
\hline 2012 & 2.826 .709 & - \\
\hline 2013 & 3.278 .598 & 0,16 \\
\hline 2014 & 3.766 .638 & 0,14 \\
\hline 2015 & $4,001,835$ & 0,06 \\
\hline 2016 & $4,927,937$ & 0,23 \\
\hline Rata -rata Pertumbuhan & 0,12 \\
\hline
\end{tabular}

Sumber: Dinas Pariwisata Provinsi Bali, 2017

Pada Tabel 1 dapat dilihat bahwa jumlah kunjungan wisatawan mancanegara ke Pulau Bali meningkat setiap tahunnya, menyebabkan meningkatnya kebutuhan produk pariwisata. Akan tetapi, presentase pertumbuhan wisatawan yang berkunjung ke Pulau Bali mengalami fluktuatsi dan rata-rata presentase pertumbuhan kunjungan wisatawan mancanegara selama lima tahun terakhir adalah $0,12 \%$.

Berdasarkan Peraturan Pemerintah Republik Indonesia Nomor 50 Tahun 2011 tentang Rencana Induk Pembangunan Kepariwisatan Nasional Tahun 2010-2025 dicantumkan bahwa kawasan Tulamben-Amed dan sekitarnya masuk kedalam daftar sebagai Kawasan Strategis Pariwisata Nasional yang berada di posisi 80 dari 88 daftar kawasan pariwisata Indonesia. Hal ini, sejalan dengan Peraturan Bupati Karangasem Nomor 31 Tahun 2015 tentang Penataan Lahan dalam Pasal 4 mengenai lokasi penataan lahan disebutkan bahwa Desa Purwakerti masuk kedalam kawasan pariwisata Tulamben yang meliputi sembilan desa di antarnya adalah Desa Bunutan, Desa Purwakerti, Desa Culik, Desa Labasari, Desa Datah, Desa Tulamben, Desa Dukuh, Desa Kubu, Desa Baturinggit dengan panjang garis pantai 23,5 kilometer.

Berdasarkan data statistik Dinas Pariwisata Provinsi Bali, daya tarik wisata Jemeluk-Amed termasuk ke dalam 15 daya tarik wisata yang terdapat di Kabupaten Karangasem. Pantai Jemeluk-Amed 
merupakan destinasi wisata tirta atau wisata bahari yang berada di Desa Purwakerti. Wisata tirta tersebut menyuguhkan barisan terumbu karang beraneka ragam jenisnya di sepanjang garis pantai dan terjaga kelestariannya. Selain itu, juga terdapat situs sejarah yang ada di bawah laut yaitu peninggalan bangkai kapal Belanda, yang diperkirakan oleh masyarakat setempat telah ada sejak zaman kolonialisme. Daya tarik lainnya adalah beraneka-ragam jenis ikan, Hasil kajian singkat Reef Check Indonesia dan Coral Reef Alliance di seluruh Bali tahun 2011 menyebutkan bahwa Teluk Jemeluk secara khusus memiliki keanekaragaman hayati laut yang tinggi terdapat lebih dari 220 spesies ikan karang yang hidup dan 181 spesies karang. Pantai ini juga memiliki terumbu karang buatan berupa patung yang ditenggelamkan dalam rangka membantu menciptakan tempat tumbuhnya karang. Penenggelaman juga dimaksudkan sebagai lokasi alternatif atraksi bawah air untuk kegiatan penyelaman galeri taman bawah laut. Menjadikan Pantai Jemeluk-Amed surga bagi para penyelam dengan air laut yang jernih dan tenang serta memiliki keindahan bawah laut yang tak terlukiskan.

Pantai Jemeluk-Amed menawarkan beragam aktivitas laut seperti, snorkling, diving, dan fishing. Namun, khusus untuk aktivitas fishing harus dilakukan sesuai peraturan yang ditetapkan, karena terdapat kawasan yang menjadi tempat persebaran terumbu karang menyebabkan ikan tangkap menjadi banyak. Masyarakat perlu membuat zonasi area dalam rangka melindungi kawasan pesisir dan laut dari ancaman-ancaman yang dapat merusak. Pembentukan zonasi ini dilakukan secara partisipatori dengan kelompok pariwisata Tunas Mekar dan kelompok nelayan Mina Prami difasilitasi oleh Desa Adat Culik dan Desa Dinas Purwakerti, Reef Check Indonesia, dan Coral Reef Alliance, melalui awig-awig Bendesa Adat zonasi ini sejalan dengan usulan pencadangan KKP di Karangasem. Hal tersebut dilakukan supaya tidak mengganggu ekosistem terumbu karang dan ikan-ikan hias yang berada di area Pantai Jemeluk-Amed.

Pantai Jemeluk-Amed merupakan sebuah destinasi wisata yang dikembangkan masyarakat dusun Banjar Lebah yang tinggal di pesisir pantai Jemeluk-Amed serta stakeholder yang melakukan bisnis di kawasan tersebut. Stakeholder tersebut diantaranya perusahaan jasa penyewaan alat diving, snorkling, homestay, villa dan restaurant. Melalui website, stakeholder tersebut melakukan promosi daya tarik wisata yang ada di pantai Jemeluk-Amed. Sampai saat ini daya tarik wisata pantai Jemeluk-Amed sudah dikenal oleh wisatawan nusantara maupun mancanegara. Adapun jumlah wisatawan mancanegara yang berkunjung ke Pantai Jemeluk-Amed dalam kurun waktu lima tahun terakhir dapat dilihat pada Tabel 2.

Tabel 2. Jumlah Kunjungan Wisatawan Mancanegara Ke Pantai Jemeluk-Amed Tahun 2011-2015

\begin{tabular}{ccc}
\hline Tahun & $\begin{array}{c}\text { Jumlah Wisatawan } \\
\text { (orang) }\end{array}$ & $\begin{array}{c}\text { Pertumbuhan } \\
(\%)\end{array}$ \\
\hline 2011 & 8.599 & - \\
\hline 2012 & 3.180 & $-1,7$ \\
\hline 2013 & 9.920 & 0,7 \\
\hline 2014 & 8.640 & 0,2 \\
\hline 2015 & 3.119 & $-1,7$ \\
\hline
\end{tabular}

Sumber : Badan Pusat Statistik Bali, 2017

Tabel 2 tentang kunjungan wisatawan mancanegara ke pantai Jemeluk-Amed dapat dilihat tingkat kunjungannya mengalami fluktuasi. Hal ini dipengaruhi oleh tingkat kunjungan wisatawan mancanegara yang datang ke bali menurun sehingga mempengaruhi tingkat kunjungan wisatawan mancanegara ke pantai Jemeluk-Amed. Tingkat kunjungan tertinggi ke pantai Jemeluk-Amed terjadi pada tahun 2013 dengan jumlah 9.920 wisatawan mancanegara.

Terletak tidak jauh dari daya tarik wisata Tulamben, pantai Jemeluk-Amed memiliki keanekaragaman biota laut yang tidak kalah indah dari wisata Tulamben. Selain itu terdapat kelebihan daya tarik wisata di pantai Jemeluk-Amed. Bagi para wisatawan pemula yang ingin menikmati keindahan alam bawah laut melalui snorkeling, wisatawan dapat melihat biota laut hanya dengan bersnorkeling di pinggir garis pantai.

Pantai Jemeluk-Amed terletak di Dusun Lebah, Desa Purwakerti, Kecamatan Abang, Kabupaten Karangasem. Desa Purwakerti merupakan desa dinas yang masuk 
ke dalam Desa Adat Culik, karena banyak dari penduduk Desa Culik yang tinggal di kawasan pantai Jemeluk-Amed. Desa Purwakerti memiliki dua banjar diantaranya adalah Banjar Lebah dan Banjar Amed.

Dalam perkembangan sektor pariwisata di Kabupaten Karangasem, termasuk destinasi wisata pantai JemelukAmed, infrastruktur sangat diperlukan sebagai pertimbangan wisatawan untuk berkunjung. Pada tahun 2016 pemerintah Kabupaten Karangasem telah membenahi infrastruktur menuju destinasi wisata tersebut sehingga memudahkan wisatawan berkunjung. Dengan infrastruktur yang baik tentunya dapat menambah pertimbangan wisatawan melakukan perjalanan wisata menuju pantai Jemeluk-Amed. Hal tersebut juga membuat investor melirik peluang bisnis di kawasan Pantai Jemeluk-Amed dengan mendirikan akomodasi perhotelan dan restaurant. Hal ini dapat mendukung kegiatan kepariwisataan di Desa Purwakerti. Hasil observasi awal peneliti terdapat 34 akomodasi penginapan di banjar Amed, kemudian ada 81 akomodasi penginapan di banjar Lebah. Banyaknya homestay dan villa menjukan bahwa daya tarik wisata pantai Jemeluk-Amed mampu menarik kedatangan wisatawan yang ingin berwisata mencari ketenangan dari kehidupan seharihari.

Daya tarik wisata Jemeluk-Amed merupakan salah satu daya tarik wisata di Pulau Bali yang mengunggulkan keindahan alam bahari atau wisata bahari didukung sejumlah fasilitas akomodasi seperti hotel dan restoran yang terdapat di sepanjang kawasan menuju pantai Jemeluk-Amed. Wisatawan yang datang ke Pulau Bali, baik individu maupun secara berkelompok, yang tertarik akan pesona bahari dan keindahan aktraksi wisata bawah air yang ditawarkan, dapat berkunjung ke daya tarik wisata JemelukAmed. Sekarang pantai tersebut menjadi daya tarik wisata yang cukup populer bagi wisatawan nusantara maupun mancanegara.

Wisatawan yang sedang mengunjungi daya tarik wisata Jemeluk-Amed tentu saja memiliki karakter dan motivasi yang berbeda. Saat ini, terdapat berbagai jenis sifat yang dapat menggambarkan karakter wisatawan seperti jenis wisatawan backpacker yang menikmati perjalanannya dengan biaya murah, semua fasilitas yang digunakan adalah fasilitas minimum. Adapun wisatawan yang memiliki budged lebih, akan bisa menginap di hotel berbintang. Advanture tourist wisatawan yang suka berpetualang di alam terbuka. Wisatawan jenis ini biasanya datang ke suatu negara dengan tujuan khusus untuk berpetualang menguji nyali, seperti mendaki gunung, menjelajah gua, bermain arung jeram, mencari ombak yang bagus untuk surfing. Wisatawan advanture ini biasanya datang secara berkelompok tidak menuntut akomodasi yang lebih dan bersedia menginap di rumah penduduk atau mendirikan tenda di tepi pantai. Aktivitas yang dilakukan oleh wisatawan dapat menunjukan karakter dan motivasi datang ke daerah wisata tersebut. Saat ini, terjadi perubahan pola konsumsi wisatawan ke jenis yang lebih tinggi, yang meskipun tetap santai tetapi dengan selera yang lebih meningkat yakni menikmati produk atau kreasi budaya (culture), peninggalan sejarah (heritage), dan alam (nature) atau ekowisata dari suatu daerah atau Negara (Poon,1993).

Potensi alam pantai Jemeluk-Amed merupakan modal dasar dikembangkanya wisata berbasis alam. Wilayah yang memiliki garis pantai dan terdiri atas laut terdapat terumbu karang yang menawan. Daratan dan pemandangan perbukitan merupakan modal alam yang sangat besar untuk berkembangnya kepariwisataan di Desa Purwakerti. Dewasa ini kedatangan wisatawan yang berkunjung tidak hanya sekedar ingin menikmati alam dan budaya yang ada, akan tetapi wisatawan ingin melakukan aktifitas fisik. Keanekaragaman ekosistem terumbu karang dan ikan dalam kawasan laut di pantai Jemeluk-Amed, sangat menjanjikan untuk ekowisata dan wisata minat khusus. Saat ini aktifitas olahraga (sport tourism) yang dilakukan oleh wisatawan di alam terbuka telah menjadi salah satu komoditi pariwisata yang mampu membuat wisatawan tinggal lebih lama di suatu daerah tujuan wisata. (Fandelli, 2002).

Berlandaskan hal tersebut, dapat diketahui bahwa perjalanan yang dilakukan wisatawan tidaklah selalu sama. Kegiatan pariwisata yang dilakukan di daerah wisata juga bisa berbeda-beda karena dipengaruhi oleh motivasi wisatawan serta kondisi tertentu. Oleh sebab itu, peneliti ingin mengetahui karakter dan motivasi wisatawan yang datang ke Pantai Jemeluk-Amed.. 


\section{METODE PENELITIAN}

Penelitian ini dilakukan di pantai Jemeluk-Amed, Desa Purwakerti, Kecamatan Abang, Kabupaten Karangasem. Dipilihnya pantai Jemeluk-Amed sebagai lokasi penelitian ini karena pantai ini merupakan salah satu destinasi wisata tirta di kawasan wisata Bali Timur (Kabupaten Karangasem) yang memiliki keunggulan alam bawah laut yang kaya.Berikut ini merupakan peta lokasi penelitian yang akan dilakukan.

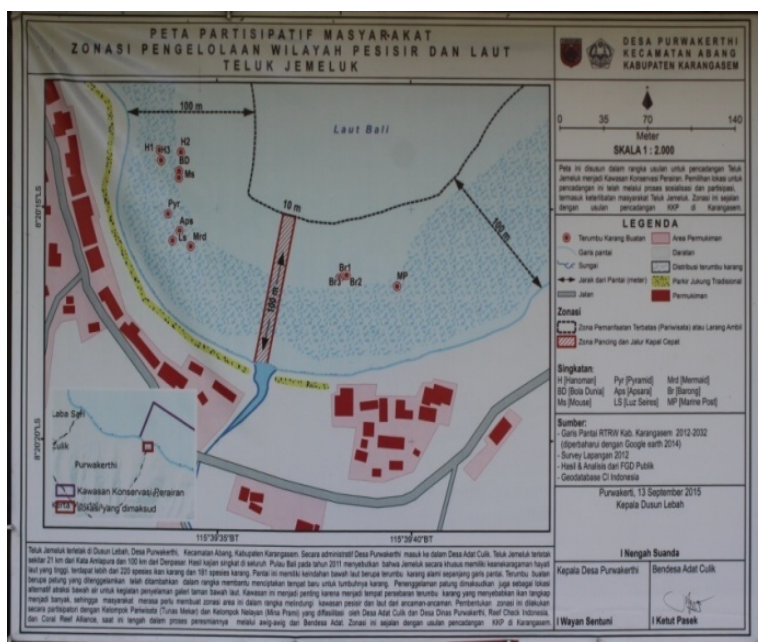

Gambar 1. Lokasi Penelitian di Pantai Jemeluk-Amed

Terdapat dua fokus pada penelitian ini yaitu pertama karakteristik wisatawan mancanegara yang berkunjung ke pantai Jemeluk-Amed. Teori-teori yang digunakan dalam penelitian ini antara lain, karakteristik perjalanan wisatawan (trip descriptor) yang akan membahas mengenai gambaran perjalanan wisatawan mancanegara dalam melakukan perjalanan dan karakteristik wisatawannya (tourist descriptor).Trip Descriptor dan Tourist Descriptor akan mengklasifikasi karakteristik wisatawan mancanegara melalui karakteristik sosio-demografis, geografis serta psikografis.

Fokus kedua adalah menganalisis motivasi wisatawan mancanegara yang berkunjung ke pantai Jemeluk-Amed, karena motivasi merupakan faktor penting bagi wisatawan dalam mengambil keputusan mengenai destinasi wisata yang akan dikunjungi. Terdapat empat faktor mengapa wisatawan melakukan perjalanan diantaranya Physical or Physiological Motivation, Fantasy Motivation, Cultural Motivation, Social Motivation. Keempat hal tersebutlah yang digunakan peneliti untuk menganalisismotivasi wisatawan mancanegara yang berkunjung ke pantai Jemeluk-Amed.

Data yang digunakan dalam penelitian ini meliputi dua jenis. Pertama, data kualitatif berupa pandangan, ungkapan, kesan. Kedua, Data kuantitatif yang diperlukan dalam penelitian ini digunakan untuk mendukung data kualitatif, antara lain data kunjungan wisatawan yang datang ke pantai JemelukAmed berdasarkan asal negara. Data kuantitatif berupa angka-angka yang diperoleh berdasarkan kualifikasi data dari hasil penyebaran kuisioner kepada responden yang berkunjung di pantai Jemeluk-Amed.

Sumber data dalam penelitian ini dapat dibagi menjadi dua yaitu data primer dan data skunder. Pertama data primer akan diambil dari sumber primer secara langsung yang dikumpulkan di lapangan melalui teknik pengumpulan data secara observasi yaitu pengamatan di lapangan, kuesioner yang diberikan kepada responden atau wisatawan mancanegara yang datang ke pantai JemelukAmed, Desa Purwakerti. Kedua, data sekunder diperoleh bukan dari pihak pertama atau yang ditemukan langsung di lapangan, namun diperoleh berasal dari buku-buku, jurnal, ataupun literatur lainnya yang dianggap relevan yang berkaitan dengan penelitian.

Metode pengumpulan data yang digunakan dalam penelitian ini ada empat macam. Metode-metode tersebut dirinci sebagai berikut. (1) Observasi adalah pengumpulan data secara langsung ke lokasi penelitian untuk mendapatkan gambaran yang jelas mengenai objek yang akan diteliti. Data yang akan diambil adalah wisatawan mancanegarayang sedang melakukan aktivitas wisata. (2) Kuesioner adalah teknik pengumpulan data dengan cara menyiapkan daftar pertanyaan kepada para pengunjung. Kuesioner disebarkan secara langsung kepada wisatawan mancanegarayang berwisata di pantai Jemeluk-Amed.(3) Wawancara adalah pengumpulan data dengan cara wawancara menanyakan secara langsung kepada informan. Dalam hal ini, pertanyaan yang diajukan disesuaikan dengan permasalahan yang dibahas. (4) Studi kepustakaan adalah teknik pengumpulan data dengan cara menelaah literatur-literatur atau buku-buku yang berhubungan dengan penelitian yang sedang dilakukan.

Sampel dalam penelitian ini, adalah wisatawan mancanegara yang berkunjung ke 
pantai Jemeluk-Amed. Teknik pengambilan sampel yang digunakan adalah teknik sampel non-random secara kebetulan. Teknik ini dilakukan terhadap orang yang kebetulan ada atau dijumpai (Wardiyanta, 2010).

Dalam penelitian ini digunakan 22 pertanyaan untuk mengukur karakteristik dan motivasi wisatawan mancanegara di pantai Jemeluk-Amed, Desa Purwakerti. Dengan responden yang diambil sebanyak 110 orang (Supranto, 2006).

Teknik analisis data yang dipergunakan adalah analisis deskriptif kuantitatif yaitu analisis yang menguraikan, menggambarkan, dan menjelaskan secara sistematis data yang diperoleh di lapangan. Sehingga memperoleh gambaran yang jelas dan objektif mengenai karakteristik, motivasi wisatawan mancanegara yang sedang berkunjung ke pantai Jemeluk-Amed.

\section{HASIL}

\section{Gambaran umum}

Pantai Jemeluk-Amed merupakan salah satu destinasi wisata bahari yang berada di kawasan pariwisata Timur Pulau Bali. Pantai Jemeluk-Amed merupakan kawasan teluk yang terletak di wilayah Banjar Amed dan Banjar Lebah, Desa Purwakerti. Secara administratif Desa Purwakerti masuk kedalam Desa Adat Culik, Kecamatan Abang Kabupaten Karangasem, Bali. Pantai JemelukAmed terletak sekitar $21 \mathrm{~km}$ dari Kota Amlapura dan sekitar $100 \mathrm{~km}$ dari Kota Denpasar. Perkembangan kawasan pantai Jemeluk-Amed menjadi daerah tujuan wisata bahari terjadi pada tahun 1980-an. Hal tersebut dikarenakan adanya keanekaragaman hayati laut.

Kekayaan hayati laut di Teluk Jemeluk-Amed mampu menopang sektor pariwisata. Pantai Jemeluk-Amed memiliki keindahan bawah laut alami sepanjang garis pantai.

Pada umumnya masyarakat yang tinggal di Desa Purwakerti berprofesi sebagai nelayan. Namun, sebagian merupakan nelayan tidak tetap karena tidak selalu melaut, ketika tidak melaut ada dari mereka yang berprofesi sebagai pemandu wisata lokal. Mereka mangantarkan wisatawan berwisata malakukan aktivitas penyelaman, snorkeling, memancing ataupun sekedar berlayar dengan perahu lokal disekitar kawasan perairan teluk. Secara umum, nelayan yang tinggal di Pantai Jemeluk-Amed berada di bawah satu organisasi, yaitu kelompok nelayan Mina Prami yang membawahi organisasi kelompok Tunas Mekar. Kelompok nelayan Tunas Mekar terdiri atas 85 anggota nelayan yang secara aktif terlibat dalam kegiatan kepariwisataan. Untuk menunggu giliran mengantar wisatawan, diatur oleh kelompok pariwisata Tunas Mekar. Bagi nelayan yang mendapat antrian mengantar wisatawan wajib membayar uang iuran kas kepada organisasi sebesar Rp. 15.000,- untuk sekali jalan mengantar wisatawan sebagai keperluan koperasi. Disamping itu, terdapat iuran $\mathrm{Rp}$. 10.000 ,- perbulan untuk keperluan hiburan. Kelompok nelayan Tunas Mekar dipimpin oleh bapak Kadek Putu Budiarta dan bapak I Ketut Suparwata sebagai sekertaris. Dalam sehari rata - rata 5 kapal jukung dari kelompok nelayan Tunas Mekar membawa wisatawan ke laut. Bagi wisatawan yang menyewa jukung untuk melakukan aktifitas pariwisata bawah laut seperti diving dan snorkling dikenakan biaya sebesar Rp. 150.000,- sekali antar dengan durasi selama 2 jam, untuk dua lokasi yang berbeda dengan kapasitas untuk aktifitas diving maksimal sebanyak 3 orang dan kapasitas maksimal untuk aktifitas snorkeling sebanyak 4 orang wisatawan.

Pada tahun 2015 masyarakat Desa Purwakerti bersama dengan kelompok nelayan Tunas Mekar dan Mina Prami melakukan zonasi pada kawasan pesisir dan laut dengan maksud untuk melindungi kerusakan terumbu karang yang difasilitasi oleh Desa Adat Culik, Reef check Indonesia dan Coral Reef Alliance melalui Awig-Awig dari Bendesa Adat. Zonasi tersebut meliputi zona 100 meter dari garis pantai. Menurut Reef Check Foundation Indonesia (2010). Setidaknya terdapat 20 perusahaan penyedia jasa selam yang beroperasi di kawasan Jemeluk-Amed.

Di pantai Jemeluk-Amed tersedia berbagai fasilitas akomodasi yang mampu menyediakan kebutuhan wisatawan berkunjung seperti restaurant, resort, villa, homestay, bungalow, dan cottage. Serta terdapat transportasi yang beroperasi ketika ada wisatawan atau yang bisa dikatakan sebagai freelance driver bagi wisatawan yang ingin pergi meninggalkan kawasan Jemeluk Amed. Transportasi yang terdapat di kawasan pantai Jemeluk-Amed sering dimanfaatkan 
oleh wisatawan untuk melanjutkan perjalanan menuju destinasi selanjutnya. Terdapat sekitar 34 akomodasi penginapan di Banjar Amed dan sekitar 81 akomodasi penginapan di Banjar Lebah. Jumlah tersebut merupakan hasil wawancara dengan kapolsek sektor Abang. Namun diperkirakan masih terdapat akomodasi penginapan yang belum terdaftar. Ini dikarenakan tidak adanya data yang tepat mengenai jumlah penginapan dan terdapat pembangunan akomodasi baru di kawasan Jemeluk-Amed.

\section{Pembahasan}

Berdasarkan hasil pengambilan data karateristik trip descriptor dan tourist descriptor dan hubungannya dengan motivasi wisatawan yang mengujungi Pantai JemelukAmed. Dapat diuraikan bahwa sesuai dengan karakteristik trip descriptor wisatawan yang datang sebagian besar merupakan wisatawan mancanegara yang mengorganisasi perjalanannya sendiri dengan menyewa kendaraan mobil atau motor. Adapun lama tinggal wisatawan yang berkunjung kebanyakan menghabiskan waktu berkunjung selama 1-3 hari, dengan memanfaatkan akomodasi homestay sebagai tempat menginap. Kebanyakan berkunjung bersama teman, dilihat dari aktifitas yang dilakukan wisatawan mancanegara yang datang ke pantai Jemeluk-Amed, melakukan aktifitas wisata diving dan snorkeling. Hal ini sesuai dengan motivasi wisatawan datang mengunjungi pantai Jemeluk-Amed dengan keinginan paling banyak melakukan aktifitas wisata sport sebagai dorongan datang berkunjung. Hal tersebut diperkuat karena pantai JemelukAmed merupakan salah satu tourist attraction yang sudah dikenal untuk melakukan aktifitas wisata bawah laut. Adapun kesesuaian motivasi wisatawan datang dengan tourist descriptor, bahwa berdasarkan motivasi wisatawan yang datang ke pantai JemelukAmed, paling banyak menyatakan berkunjung untuk bersenang-senang (pleasure), yang dapat diartikan juga segala kegiatan fisik maupun mental. Dilihat rata - rata umur wisatawan mancanegara yang berkunjung adalah rentang usia 26 - 35 tahun dan paling banyak berasal dari Benua Eropa. Wisatawan yang melakukan kunjungan ke suatu tourist attraction tentunya memiliki waktu luang untuk dihabiskan di pantai Jemeluk-Amed. Hal ini sesuai dengan pendapat Jackson dan Burton
(1999), Leisure merupakan sebuah aktifitas untuk pencarian atau ekspedisi ke tempat tempat yang menyenangkan dan untuk kegiatan pemenuhan kesenangan.

\section{SIMPULAN DAN SARAN Simpulan}

Berdasarkan hasil dan pembahasan mengenai karakteristik dan motivasi wisatawan mancanegara yang berkunjung ke pantai Jemeluk-Amed. Dapat dibuat simpulan hasil penelitian sebagai berikut. Secara umum wisatawan yang berkunjung ke Pantai Jemeluk-Amed melakukan perjalanannya dalam kelompok kecil, bersama pasangan, teman atau keluarga. Untuk bisa sampai ke pantai Jemeluk-Amed kebanyakan datang dengan menyewa kendaraan roda empat dan mengorganisasi perjalanan sendiri. Wisatawan datang ke pantai Jemeluk-Amed dan menginap 1-3 hari, Jenis akomodasi yang dipilih berupa homestay.

1. Karakteristik wisatawan mancanegara yang berkunjung ke pantai JemelukAmed di dominasi oleh wisatawan usia 26 - 35 tahun dan berjenis kelamin laki laki yaitu 53.64\%. Status perkawinannya sudah menikah berjumlah $55.45 \%$ wisatawan. Paling banyak berasal dari Benua Eropa didominasi oleh wisatawan berasal dari Perancis sebesar $25.45 \%$ dan rata - rata tingkat pendidikan adalah sarjana. Sebagian besar bekerja sebagai pegawai swasta atau wiraswasta. Wisatawan yang berkunjung mendapatkan sumber informasi dari teman berjumlah $76.36 \%$ dan tidak menggunakan paket tur. Wisatawan memanfaatkan moda transportasi kendaraan sewaan berupa mobil berjumlah $94.55 \%$. Rata-rata pengeluaran perhari sebesar $\$ 119.27$ dollar atau sebesar Rp. 1.547.000 rupiah (dengan asumsi rupiah Rp.13.000). Lama tinggal wisatawan yang berkunjung paling banyak dilakukan selama 1-3 hari $78.18 \%$. Wisatawan yang berkunjung ke pantai Jemeluk-Amed merupakan jenis wisatawan drifter atau baru berkunjungan untuk pertama kali berjumlah $81.82 \%$, wisatawan melakukan kunjungan bersama teman berjumlah 53.64\%. Aktivitas wisatawan selama berkunjung di Pantai Jemeluk-Amed paling banyak adalah snorkeling berjumlah $49.09 \%$. Wisatawan 
yang berkunjung umumnya menyukai keindahan dan suasana tenang serta keunikan dan menikmati berbagai macam jenis keindahan bawah laut Teluk Jemeluk.

2. Berdasarkan motivasi wisatawan mancanegara yang berkunjung ke Pantai Jemeluk-Amed, Desa Purwakerti, Kecamatan Abang, maka diperoleh hasil sebagai berikut .

a. Terdapat $45(40.91 \%)$ wisatawan menyatakan keinginan untuk melakukan sport seperti diving, snorkeling, dan canoeing sebagai motivasi penyaluran hobi demi kepuasan batin.

b. Terdapat $31(28.18 \%)$ wisatawan menyatakan motivasi bersenang senang untuk penyegaran diri untuk memulihkan kembali semangat (fisik dan mentalnya).

c. Terdapat $13(11.82 \%)$ wisatawan mancanegara menyatakan motivasi rekreasi berkunjung ke Pantai Jemeluk-Amed untuk mencari hiburan dengan memanfaatkan waktu senggang berkunjung bersama pasangan, teman maupun keluarga.

d. Terdapat delapan (7.27\%) wisatawan mancanegara menyatakan motivasi berkumpul bersama teman atau keluarga dikarenakan kesibukan yang yang berbeda dan memilih Pantai Jemeluk-Amed dapat menciptakan suasana yang menyenangkan.

e. Terdapat tujuh $(6.36 \%)$ wisatawan mancanegara menyatakan motivasi untuk melihat peninggalan sejarah Pantai Jemeluk-Amed menjadi motivasi mereka berkunjung, karena terdapat bangkai kapal yang karam di kawasan laut teluk Jemeluk.

f. Terdapat enam (5.45\%) wisatawan mancanegara menyatakan motivasi untuk mencari pengalaman baru. Adanya perbedaan geografis dengan negara wisatawan menjadi faktor pilihan mencari hal yang belum pernah diketahui.

Berdasarkan motivasi tersebut, motivasi dominan mendorong wisatawan mancanegara berkunjung ke pantai JemelukAmed adalah motivasi sport berjumlah 40.91\% menginginkan melihat atraksi bawah laut serta keindahan dan keanekaragaman ikan dan karang Pantai Jemeluk-Amed yang terkenal di Pulau Bali.

\section{Saran}

Berdasarkan hasil penelitian ini, maka dapat diberikan beberapa masukan pemikiran atau saran terkait karakteristik dan motivasi wisatawan yang berkunjung ke Pantai Jemeluk-Amed sebagai berikut.

1. Pemerintah Kabupaten Karangasem diharapkan mendukung pengembangan wisata tirta pantai Jemeluk-Amed sebagai daya tarik wisata di Karangasem, Dengan membangun infrastruktur jalan dan sarana transportasi umum.

2. Bagi kelompok nelayan Mina Prami dan Tunas Mekar sebagai pengelola wisata tirta ini perlu menjaga kelestarian alam bawah laut pantai Jemeluk-Amed dan sebagai pemandu wisata lokal sebaiknya menambah kemampuan berbahasa asing.

3. Untuk Desa Purwakerti perlu memberdayakan sumber daya masyarakat lokal, memperhatikan kebutuhan wisatawan dalam menggembangkan wisata tirta di Desa Purwakerti. Menyediakan area parkir dan melakukan promosi daya tarik wisata Pantai JemelukAmed berkerjasama sama dengan para pelaku pariwisata.

4. Bagi akademisi, penelitian ini masih jauh dari sempurna sehingga perlu adanya penelitian lanjutan yang lebih mendalam. 


\section{Kepustakaan}

Allen, Gerald R., and Mark V. Erdmann. 2011."Reef fishes of Bali, Indonesia." Bali Marine Rapid Assessment Program . pp.15-68

Alejziak, W. 2013. Tourist activity inhibitors. International Journal of Culture, Tourism and Hospitality Research, 7(1). pp.1-27.

Aristiarini, Putu Lilis, and I. Mahagangga. "Peranan Masyarakat Nelayan Dalam Aktivitas Kepariwisataan Di Pantai Jemeluk Desa Purwakerti Kecamatan Abang Kabupaten Karangasem." Jurnal Destinasi Pariwisata 3.1. pp.9-16.

Boberg, A. 2010. A Study on Swedish Charter Tourists Behaviour and Acting: Case: Gran Canaria, Spain.

Badan Pusat Statistik Provinsi Bali. 2014. Bali Dalam Angka. Denpasar: BPS Bali.

Faruk, Nuray, Ali Selcuk, Sevgi. 2013. Basic Characteristic, Motivations, And Activities Of Ecotourist: A Case Of Lake van Basin Area, Turkey. International Jurnal of Social Science, Vol. 6.pp.91-107

Fandeli, Chafid. 2002. Perencanaan Kepariwisataan Alam. Fakultas Kehutanan UGM, Yogyakarta.

Hadinoto, Kusudianoto. 1996. Perencanaan Pengembangan Destinasi Pariwisata. Jakarta: UI Press.

Ignasius, Suradin. 2012. Karakteristik dan Motivasi Wisatawanyang Berkunjung ke Taman Nasional Komodo Kabupaten Manggarai Barat. NTT. (Sebuah Laporan Akhir) Fakultas Pariwisata Universitas Udayana.

Jaswandi, Lathiffida Noor. 2014."Kesesuaian pengembangan desa wisata Subak Jatiluwih dengan motivasi wisatawan."

Kusmayadi, Endar Sugiarti. 2000. Metodologi Penelitian Dalam Bidang Kepariwisataan. Jakarta: Garmedia Pustaka.

Kwan, P., Eagles, P. F., \& Gebhardt, A. 2010. Ecolodge patrons' characteristics and motivations: A study of Belize. Journal of Ecotourism, 9(1). pp.1-20.

Lindenberg. 2001. Intrinsic Motivation in A New Light. Journal of International review for social sciences, vol 54.
Marpaung, Happy. 2002. Pengantar Pariwisata. Bandung: Alfabeta

Meyers, Koen. 2009. Panduan Dasar Pelaksanaan Ekowisata. Jakarta: Unesco Office.

McIntosh, R. W. 1972. Tourism, Principles,Practices, Philosophies. Ohio: Inc Press.

Moeloeng, Lexy J. 2001. Metode Penelitian Kualitatif. Bandung: RemajaRosdakarya.

Mohammad, B. A. M. A. H., \& Som, A. P. M. 2010. An analysis of push and pull travel motivations of foreign tourists to Jordan. International Journal of Business and Management, 5(12). p.41.

Murphy, P.E. 1985. Tourism: A Community Approach. New York and London: Routledge.

Pendit, Nyoman S. 1994. Ilmu Pariwisata Sebuah Pengantar. Jakarta: PT. PradyaParamitha.

Pitana, I Gede; Gayatri, Putu. 2005. Sosiologi Pariwisata. Yogyakarta: Andi Offset

Poon, A. 1993. Tourism, Technology and Competitive Strategies. Oxford: CABInternational

Purwati, F., \& Ibrahim, M. 2016. Motivasi Wisatawan Berkunjung Ke Pantai Indah Sergang Dabo Singkep. Jurnal Online Mahasiswa (JOM) Bidang Ilmu Sosial dan Ilmu Politik, 3(2), 1-14.

Saputra, I Gede Gian. 2013. Aktivitas Wisatawan Eropa First Timer dan Repeater di Desa Ubud. (Sebuah Laporan Akhir). Fakultas Pariwisata Universitas Udayana.

Seaton, A. V; Bennet. 1996. Marketing Tourism Product. UK: CengageLeaming

Sigiani. 1998. Teori Motivasi dan Aplikasi. Jakarta: Rineka Cipta

Sihite, Richard. 2000. Tourism Industry. Surabaya: SIC

Simarangkir, Omega Raya. 2015. Kajian Resiliensi Pasca Pemutihan Karang Sebagai Dasar Pengelolaan Terumbu Karang Berkelanjutan (Studi Kasus Pesisir Amed Bali). Diss. Bogor Agricultural University (IPB).

Siri, R., Kennon, L., Josiam, B., \& Spears, D. 2012. Exploring Indian Tourists Motivation and Perception Of Bangkok. Tourismos, 7(1). 
Smith, C. and Jenner, P. 1997. The Seniors Travel Market. Travel and Tourism Analyst.

Suardana, I. W., \& Sudiarta, I. N. 2017. Impact of tourism to poverty in tourism destination: Pro poor tourism management approach. Journal of Business on Hospitality and Tourism, 2(1), pp.65-75.

Sugiyono. 2014. Motode Penelitian Kuantitatif Kualitatif dan $R \& D$. Bandung: Alfabeta

Sulaksmi, Rita. 2007. Analisis dampak pariwisata terhadap pendapatan dan kesejahteraan masyarakat sekitar kawasan Taman wisata alam Laut Pulau Weh Kota Sabang.

Supranto, J MA. Statistik Teori dan Aplikasi. Jakarta: Erlangga

Suwantoro, Gamal. 1997. Dasar-dasar Pariwisata. Yogyakarta: Andi Offset

Suwena, IKetut dan Widyatmaja, Ngr I Gst. 2010. Ilmu Pariwisata. Denpasar :Udayana University Press.

The World Tourism Organisazion (UNWTO). (n.d) Understanding Tourism: Basic Glossary.

Undang-Undang Tentang Kepariwisataan No.10 Tahun 2009

Usman, Husaini dan Purnomo Setiadi Akbar. 2009. Metode Penelitian Sosial. Jakarta: Bumi Aksara

Wahab, Solichin Abdul. 1997. Analisis Kebijakan Dari Formulasi Ke Implementasi. Kebijaksanaan Negara. Jakarta: Bumi Aksara

Wahmuji. 2008. Kamus Besar Bahasa Indonesia. Jakarta: Gramedia Pustaka.

Wardiyanta. 2010. Metode Penelitian Pariwisata. Yogyakarta: Andi Offset

Williams. Allan M, Shaw, Gareth. 1997. The Rise and Fall of British Coasted Resort: Cultural and Economic Prespective. London: Marsell.

www.kemepar.go.id//tahun-2019-industripariwisata-menjadi-penghasil-devisanegara-terbesar-di-indonesia. Diakses 4 februari 2017. 